International Journal of Cancer Studies \& Research (IJCR) ISSN:2167-9118

\title{
Efficacy of 0.5\% 5-Fluorouracil Cream and Absence of Undesirable Secondary Effects in the Treatment of Grade III Actinic Keratoses in the Presence of 5\% Dobesilate
}

Cuevas $\mathrm{P}^{1^{*}}$, Espinoza $W^{2}$, Pérez $\mathrm{C}^{3}$, Angulo ${ }^{4}$, Giménez-Gallego $\mathrm{G}^{5}$

${ }^{1}$ Facultad de Medicina, Universidad Alfonso X, Madrid, Spain.

${ }^{2}$ Dermatología, Hospital Universitario Ramón Cajal; Madrid, Spain.

${ }^{3}$ Farmacia, Hospital Universitario Ramón Cajal; Madrid, Spain.

${ }^{4}$ Investigación, Hospital Universitario Ramón y Cajal; Madrid, Spain.

${ }^{5}$ Departamento de Estructura Función de Proteínas, Centro de Investigaciones Biológicas, CSIC, Madrid, Spain.

\section{Abstract}

Background: 5-Fluorouracil (5-FU) has been a standardized topical treatment for actinic keratosis (AK) lesions, however to treat deep and hyperkeratotic AK a long treatment time is often required. Furthermore, in grade III variant AK, 5-FU normally shows a clear inefficacy. In addition, the drug can cause important inflammatory reactions and scarring. Previous studies performed at our institution reveal that topical potassium dobesilate cream counteracts efficiently skin inflammation. Objective: We propose a combinatorial application of fluorouracil and potassium dobesilate to increase the short-term clearance of grade III AK lesions without cutaneous secondary reactions.

Methods: A cream containing 5-FU $0.5 \%$ and potassium dobesilate $5 \%$ was applied twice daily for 4 to 8 weeks to grade III variant of AK lesions located in the scalp and in the face. The cream was prepared at the Pharmacy Service of the Hospital Universitario Ramón y Cajal in Madrid, Spain. Formulation didn't contain any keratolytic agent. The lesions were evaluated at an initial baseline visit and every week during 8 weeks. For follow-up observation, patients were also clinically evaluated six months after treatment.

Results: There was a $100 \%$ clearance rate $(12 / 12)$ of AK lesions treated with $0.5 \%$ fluorouracil and $5 \%$ potassium dobesilate cream. Moreover, the cosmetic outcome was excellent.

Keywords: Actinic Keratosis; Dobesilate; Flurouracil; Combinatorial Application; Fibroblast Growth Factor.

Abbreviations: FGF: Fibroblast Growth Factor; AK: Actinic Keratosis; FU: Fluorouracil.

\section{*Corresponding Author:}

Cuevas P,

Facultad de Medicina, Universidad Alfonso X, Madrid, Spain.

E-mail: pedro.cuevas44@gmail.com

Received: October 11, 2015

Accepted: October 30, 2015

Published: November 05, 2015

Citation: Cuevas P, et al., (2015) Efficacy of 0.5\% 5-Fluorouracil Cream and Absence of Undesirable Secondary Effects in the Treatment of Grade III Actinic Keratoses in the Presence of 5\% Dobesilate. Int J Cancer Stud Res. S3:001, 1-3. doi: http://dx.doi.org/10.19070/2167-9118SI03001

Copyright: Cuevas $\mathbf{P}^{\odot}$ 2015. This is an open-access article distributed under the terms of the Creative Commons Attribution License, which permits unrestricted use, distribution and reproduction in any medium, provided the original author and source are credited.

\section{Introduction}

Actinic keratosis $(\mathrm{AK})$ is an intraepidermal squamous skin cancer (SCC) in evolution [1-3] with increasing incidence worldwide. Data from the United States reported that prevalence rates were up to $26 \%$ [4], whereby a highest prevalence rate of $55 \%$ and $37 \%$ in men and women respectively aging $30-70$ years occurs in
Australia [5]. AK is the second most common diagnosis made by dermatologists. It has been estimated that more than 8.2 million visits to physicians in the United States were related to AK [6].

Treatment modalities available for $\mathrm{AK}$ treatment include destructive procedures, such as cryotherapy, curettage and electrodessication, chemical peels, photodynamic therapy, and topical therapies, including 5-fluorouracil (5-FU), imiquimod, and diclofenac [7]. In addition to standard topical monotherapy, combinations of two concomitant or sequential therapies and alternative dosing regimens have been studied in a number of clinical trials [8]. Such therapeutic modalities are used to maintain or enhance efficacy while improving tolerability, convenience, and/or patient adherence.

Recently a new $0.5 \% 5$-FU cream has been developed, alternative to the more highly concentrated topical formulations of 5-FU currently employed. It has been shown that topical application of $0.5 \% 5$-FU cream once daily for 2-4 weeks was more effective for grade I and grade II variants of AK than the $5 \%$ cream in reducing the number of AK lesions [9]. Nevertheless, grade III AK lesions continue showing completely unresponsive to any of the two forms of 5-FU treatment. Noteworthy, in spite to the differences in efficacy, both treatment modalities associate with similar degrees of skin irritation $[8,9]$. 
Previously we have reported that a $5 \%$ potassium dobesilate cream constitutes an efficient anti-proliferative and anti-irritant drug with positive keratolytic activity $[10,11]$. In this report we present a preliminary assessment of efficacy and safety of a twice daily application during 8 weeks of the combination of $0.5 \%$ 5 -FU and $5 \%$ potassium dobesilate in patients with grade III AK lesions located in the face and the scalp. This was a study carried out at a single academic hospital.

\section{Patients and Treatment}

After approval of our institutional ethical committee, 12 male patients from 63 to 80 years with a single grade III AK lesion in the scalp and in the face were enrolled $(\mathrm{n}=11)$ to receive a cream treatment. ( $5 \%$ potassium dobesilate and $0.5 \% 5-\mathrm{FU})$. Only one patient presented two adjacent AK lesions in the scalp. During the baseline visit patients signed an informed consent form, which includes a comprehensive proposed procedure. The cream was prepared at the Pharmacy Service of the Hospital Universitario Ramón y Cajal in Madrid, Spain. Formulation didn't contain any keratolytic agent. Patients applied cream in the morning and at night for 4-8 consecutive weeks. The patients were seen for follow-up visits every week. In each of these visits, photographs were taken, and the lesions were evaluated for erythema, ulceration, tenderness, swelling, necrosis, scar and pigmentation. The patients also evaluated the treatment site on each visit for cosmetic appearance, pain, itching and burning. For follow-up observation patients were clinically evaluated six months after treatment.

\section{Results and Discussion}

At the end of the treatments, a $100 \%$ clearance rate $(12 / 12)$ of $\mathrm{AK}$ lesions treated with $0.5 \% \mathrm{FU} / 5 \%$ potassium dobesilate cream was observed, as exemplified in Figure 1. Individual AK lesions cleared at different times of treatment. In some cases an apparent complete clearance was observed 4 days after initiation of the treatment (Figure 1, panels A and B). A surprisingly fast clearing effect has also been previously observed in the treatment with potassium dobesilate of grade $<$ III AK cases [11]. There was excellent cosmetic outcome with absence of local irritation, erythema and ulceration. No recurrence was observed so far over a six months-period of follow-up.

The ultimate objective of $\mathrm{AK}$ treatment is the complete removal of tumor cells as well as the functional and cosmetic preservation of the skin. Previously we reported that a $5 \%$ potassium dobesilate cream constitutes an efficient skin anti-irritant in addition to anti-keratotic drug $[10,11]$. Dobesilate is an inhibitor of fibroblast growth factor (FGF) [12], a cytokine that promotes the proliferation of neuroectodermal and mesodermal lineage cells and upregulates the potent proinflammatory phospholipid platelet-activating factor (PAF) [13]. It has also been shown that dobesilate inhibits in a time-and concentration-dependent manner the PAF production by mechanisms at that time unknown [14]. Furthermore, PAF has been implicated in inflammatory responses after 5-FU based cancer chemotherapy [15]. So, we suggest that antiPAF activity of dobesilate may be involved in the absence of inflammatory response in 5-FU-treated AK patients. To explain the high efficacy of the $0.5 \% 5-\mathrm{FU} / 5 \%$ dobesilate cream, the effect of dobesilate by itself on the AK lesions probably should be also taken into account. Actually, treatment with potassium dobesilate $5 \%$ cream for 16 weeks induced complete regression in $70 \%$ of the cases of a group of patients (46 patients -12 women and 34 men from 64 to 90, mean age 76.9 years) with AKs grade I, II and III clinical variants [11].

In this report we present a preliminary assessment of efficacy and

Figure 1. Efficacy of topical application of $5 \%$ potassium dobesilate and $0.5 \% 5$-FU cream in grade III AK lesions. Appearance of AK lesions before (left row) and after (right row) treatment. Pictures were taken at 4 days (B), 4 weeks (D) and 8 weeks (F) after the initiation of the treatment.
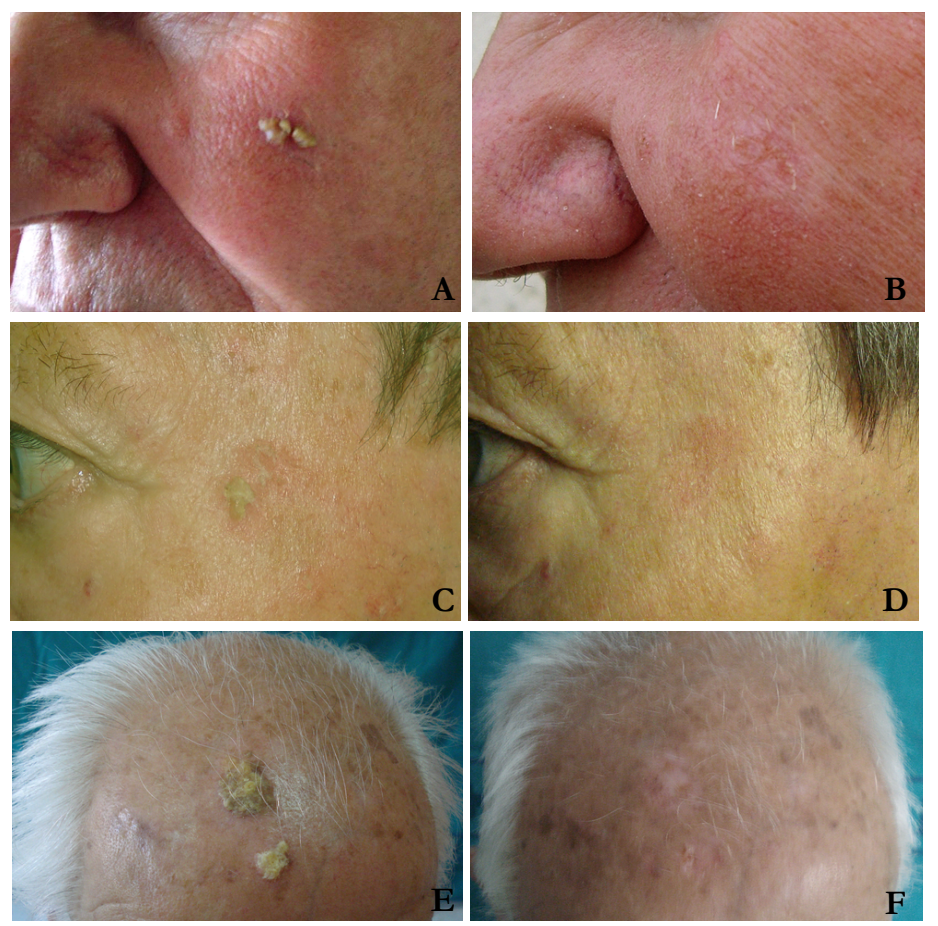
safety of a twice daily application during 4-8 weeks of the combination of $0.5 \% 5-\mathrm{FU}$ and $5 \%$ potassium dobesilate cream in patients with grade III AK lesions located in the face and the scalp. Although further large-scale therapeutic trials with excisional biopsy of the treated AK site at the end of treatment and follow-up studies are necessary to definitively establish the efficacy of this treatment modality, the results presented in this report seem a solid support for undertaking these trials.

\section{References}

[1]. Ackerman AB (2003) Solar keratosis is squamous cell carcinoma. Arch Dermatol 139(9): 1216-1217.

[2]. Lober BA, Lober CW (2000) Actinic keratosis is squamous cell carcinoma. South Med J 93(7): 650-655.

[3]. Hurwitz RM, Buckel LJ (2010) Actinic keratosis on a continuum with squamous cell carcinoma. Arch Dermatol 146(8): 923-924.

[4]. Salasche SJ (2000) Epidemiology of actinic keratoses and squamous cell carcinoma. J Am Acad Dermatol 42(1 Pt 2): 4-7.

[5]. Frost C, Williams G, Green A (2000) High incidence and regression rates of solar keratoses in a Queenland community. J Invest Dermatol 115(2): 273-277.

[6]. Cohen JL (2010) Actinic keratosis treatment as a key component of preventive strategies for nonmelanoma skin cancer. J Clin Aesthet Dermatol 3(6): 39-44.

[7]. Berlin JM (2010) Current and emerging treatment strategies for the treatment of actinic keratosis. Clin Cosmet Investig Dermatol 3: 119-126.

[8]. Ulrich M, Drecoll U, Stockfleth E (2010) Emerging drugs for actinic keratosis. Expert Opin Emerg Drugs 15(4): 545-555.

[9]. Moore AY (2009) Clinical applications for topical 5-flurouracil in the treat- ment of dermatological disorders. J Dermatolog Treat 20(6): 328-325.

[10]. Cuevas P, Angulo J, Giménez-Gallego G (2011) Topical treatment of contact dermatitis by pine processionary caterpillar. BMJ Case Rep doi:10.1136/ bcr.06.2011.4351.

[11]. Cuevas P, Espinoza W, Pérez c, Angulo J, Giménez-Gallego G (2011) Topical treatment of actinic keratoses with potassium dobesilate $5 \%$ cream. A preliminary open-label study. Eur J Med Res 16(2): 67-70.

[12]. Fernández IS, Cuevas P, Angulo J, López-Navajas P, Canales-Mayordomo A, et al. (2010) Gentisic acid, a compound associated with plant defence and a metabolite of aspirin, heads a new class of in vivo FGF inhibitor. J Biol Chem 285(15): 11714-11729.

[13]. Kanazawa S, Tsunoda T, Onuma E, Majima T, Kagiyama M, et al. (2001) VEGF, basic FGF and TGF-beta in Crohn's disease and ulcerative colitis: a novel mechanism of chronic intestinal inflammation. Am J Gastroenterol 96(3): 822-828.

[14]. Bussolino F, Biffignandi P, Arese P (1986) Platelet-activating factor - A powerful lipid autacoid possibly involved in microangiopathy. Acta Haematol 75(3): 129-140.

[15]. Stafforini DM, McIntyre TM, Zimmerman GA, Prescott SM (2003) Platelet-activating factor, a pleiotrophic mediator of physiological and pathological processes. Crit Rev Clin Lab Sei $40(6): 643-672$.

Special Issue on

"Tumor Biology and Treatment of Cancer"

Theme Edited by:

Clement G. Yedjou, Jackson State University, USA

E-mail: clement.yedjou@jsums.edu 